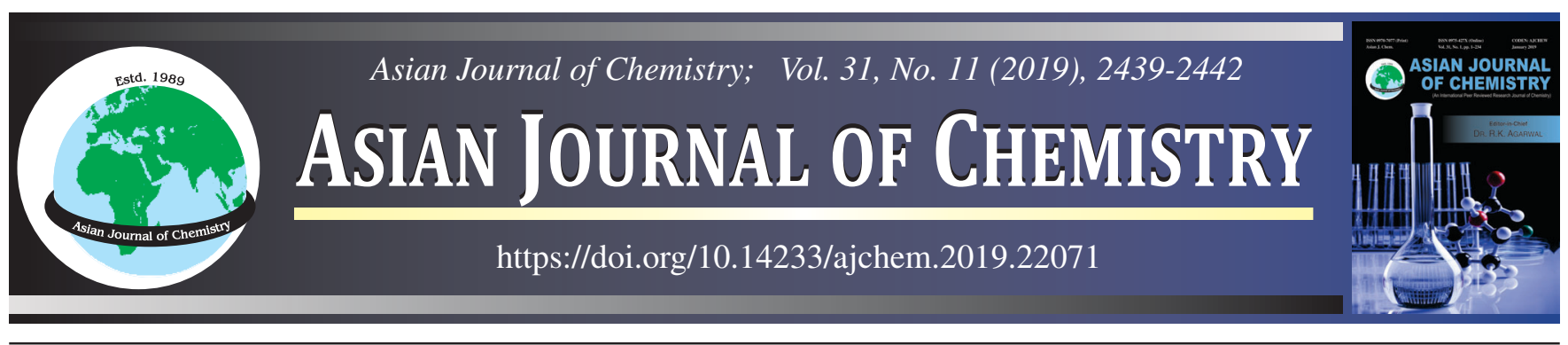

\title{
Green Synthesis of Silver Nanoparticles using Polyalthia longifolia \\ Stem Bark Extract and its Catalytic Reduction of 4-Nitrophenol
}

\author{
Karuppiah Muthu*, B. Akilandaeaswari and S. Mangala Nagasundari
}

Department of Chemistry, Manonmaniam Sundaranar University, Abishekapatti, Tirunelveli-627012, India

*Corresponding author: Fax: +91 462 2334363; E-mail: karu.muthu@yahoo.com

Received: 13 March 2019;

Accepted: 23 April 2019;

Published online: 28 September 2019;

AJC-19565

In this present study, green synthesis of silver nanoparticles (AgNPs) was synthesized from silver nitrate using the reducing agents of Polyalthia longifolia bark extract and applied the catalyst in the reduction/degradation of environmental polluted organic compound in the presence of $\mathrm{NaBH}_{4}$. Initially, the colourless reaction mixture was slowly changed to yellowish brown, UV-visible spectroscopy of surface plasmon resonance centre at $447 \mathrm{~nm}$ confirmed the formation of AgNPs. High resolution transmission electron microscopy (HRTEM) clearly identified the spherical shapes nanoparticles with diameters sizes 5-25 nm. This AgNPs has excellent catalyst in the catalytic reduction of 4-nitrophenol (4-NP) to 4-aminophenol (4-AP) as compared to the reducing agent of $\mathrm{NaBH}_{4}(\mathrm{chemical)}$ and plant extract (natural).

Keywords: Polyalthia longifolia, Silver nanoparticles, Catalytic reduction.

ᄂ - - - - - - - - - - - - - - - - - - - - - - - - - - - -

\section{INTRODUCTION}

Nanotechnology is a predominant growing research area of science and technology. Generally, metal nanoparticles are gaining in essential uses of photonics, optics, bio-labelling and catalysis [1-3]. AgNPs have found incredible applications in the area of medicine, electronics, catalysis, biosensor, drug delivery, etc. [4]. Specifically, the biological synthesis of AgNPs has been demonstrated as non-toxic, cost effective, environmental eco-friendly, an alternative to physico-chemical method. Recently, Sorghum bran [5], Ixora coccinea [6], Areca catechu [7], Bunium persicum [8], Achillea millefolium [9], etc. plant extract have been used for the synthesis of AgNPs and its potential applications.

Nowadays, various organic compounds are widely used in textile, paint, food, cosmetics, pharmaceutical, plastic and paper industries for aesthetic and other purposes. For example, 4-nitrophenol can also be used to synthesize drugs, pesticides, explosives, etc. has been listed in the top 150 hazardous and toxic species by the United State Environmental Protection Agency [10]. The hazardous and toxic pollutants of organic wastewater are produced several diseases in human and animals
[11]. Several physico-chemical methods such as adsorption, photocatalytic degradation, ion exchange, electrochemical reduction method are found to be tedious, lower production efficiency and higher operation cost [12-14]. So we can develop an alternative method of green synthesized AgNPs as a catalyst.

Polyalthia longifolia is a large genus of shrubs belonging to the family Annonaceae. This plant has been widely used in the traditional medicine for the treatment of skin disease, fever, diabetes, hypertension, etc. [15]. The plant contains important phytochemical constituents such as terpenoids, alkaloids, saponins and phenolic compounds of flavonoids [16]. These phytochemicals are significant in pharmacological activities like antiulcer, antimicrobial, anticancer, antipyretic and antiinflammation [17]. Recently P. longifolia leaf extract along with D-sorbitol used the green synthesis of AgNPs with sizes $15-20 \mathrm{~nm}$ [18]. In the present investigation, we have developed energy efficient eco-friendly green synthesis of AgNPs from P. longifolia stem bark extract that avoids organic toxic waste. The obtained AgNPs was used as a catalysis in the catalytic reduction of 4-nitrophenol to 4-aminophenol in the presence of excess amount of $\mathrm{NaBH}_{4}$, which acts as an electron donor.

This is an open access journal, and articles are distributed under the terms of the Attribution 4.0 International (CC BY 4.0) License. This license lets others distribute, remix, tweak, and build upon your work, even commercially, as long as they credit the author for the original creation. You must give appropriate credit, provide a link to the license, and indicate if changes were made. 


\section{EXPERIMENTAL}

Preparation of stem bark extract and preliminary phytochemical analyses: The fresh $P$. longifolia stem barks were collected and thoroughly washed with running tap water followed by distilled water. The bark were taken in a $250 \mathrm{~mL}$ Erlenmeyer flask, added $100 \mathrm{~mL}$ of distilled water, boiled at $80^{\circ} \mathrm{C}$ for $0.5 \mathrm{~h}$, and then filtered using Whatman's filter paper. One part of filtrate was concentrated and the standard preliminary phytochemicals were analyzed. Another part of the extract was stored at $4{ }^{\circ} \mathrm{C}$ for further use of the biosynthesis of AgNPs.

Green synthesis of AgNPs using Polyalthia longifolia bark extract: In a typical method, biosynthesis of AgNPs was synthesized from aqueous silver ions $(7 \mathrm{~mL})$ in the presence of reducing agent of $P$. longifolia bark extract $(0.5 \mathrm{~mL})$. Principally, the colourless reaction mixture changes to yellowish brown that visually determined the formation of AgNPs (Fig. 1A). P. longifolia bark extracts ( $401 \mathrm{~nm})$, aqueous silver ions (no peak) and AgNPs (447 nm) were individually recorded UV-visible spectrum as shown Fig. 1A. The preliminary test identified the colour changing reaction mixture, which was periodically recorded by UV-visible spectra, the wavelength region at $447 \mathrm{~nm}$ (Fig. 1B) the absorbance was slowly increased to confirm the formation of AgNPs [19]. After $12 \mathrm{~h}$, the maximum amount (99\%) of Ag ions was reduced to AgNPs, using UVvisible SPR peak at $447 \mathrm{~nm}$ absorbance were confirmed.

Characterization of AgNPs from P. longifolia bark extract: The formation of AgNPs was confirmed and characterized by UV-visible spectra, XRD and HRTEM technique. Preliminary analysis of the formation of AgNPs was monitored by Perkin Elmer Lambda 25 model UV-visible spectrophotometer at different time intervals in the wavelength region at 200-800 nm. The phase range of AgNPs was determined by PANanalytical X'PERT-PRO powder X-ray diffractometer with $\mathrm{Cu}-\mathrm{K} \alpha$ radiation $(40 \mathrm{kV}$ and $30 \mathrm{~mA})$. The performed AgNPs sizes and shapes was determined by high resolution transmission electron microscope (TECNAI T30 $\mathrm{G}^{2} \mathrm{~S}$-TWINFEI Company, Netherlands and Serial No: D905) operated at accelerating voltage $250 \mathrm{kV}$.



Catalytic reduction of 4-nitrophenol to 4-aminophenol: The catalytic performance of the green synthesized AgNPs was checked by the reduction of 4-nitrophenol to 4-aminophenol in the presence of $\mathrm{NaBH}_{4}$. In a typical procedure, 0.2 $\mathrm{mL}$ of freshly prepared $\mathrm{NaBH}_{4}(0.1 \mathrm{M})$ solution was added into $50 \mu \mathrm{L}$ of 4-nitrophenol $(5 \mathrm{mM})$ solution and made upto $3.0 \mathrm{~mL}$ by adding the required amount of distilled water. Afterwards, $50 \mu \mathrm{L}$ of AgNPs solution was added to the reaction mixture in a $3.5 \mathrm{~mL}$ standard quartz cuvette. For the uncatalyzed reaction, $50 \mu \mathrm{L}$ of AgNPs was replaced by adding an equal amount of triple distilled water. The reduction reaction was monitored by UV-visible spectra in the wavelength range at 650 to 250 $\mathrm{nm}$ at the desired temperature $\left(25^{\circ} \mathrm{C}\right)$.

\section{RESULTS AND DISCUSSION}

XRD and HRTEM analyses of AgNPs: Fig. 2 shows the numbers of diffraction peaks at $38.65^{\circ}, 44.45^{\circ}, 64.61^{\circ}$ and $77.74^{\circ}$ which corresponds to lattice planes at (111), (200), (220) and (311) indicates the face centered cubic (fcc) structure of silver. This result was corroborated with the database of JCPDS file no. 89-3722. It may be thought that few unassigned peaks $(*)$ are identified due to the crystallization of bioorganic phases that occur on the surface of the nanoparticles [6]. The XRD data were used for the theoretical calculation of crystalline AgNPs mean size by the Debye-Scherrer formula (1):

$$
\mathrm{D}=\frac{\mathrm{k} \lambda}{\beta \cos \theta}
$$

where $\mathrm{D}$ is the mean diameter of the nanoparticles, $\lambda$ is the wavelength of $X$-ray radiation source, $\beta$ is the angular full width half maximum (FWHM) of the XRD peak at the diffraction angle, $\mathrm{k}$ is the Scherrer's constant and $\theta$ is the Bragg's angle. The calculated average size of the nanoparticles is $\sim 28 \mathrm{~nm}$. The HRTEM analysis shows at lower magnification image (Fig. 3A) and at higher magnification image (Fig. 3B \& C), were clearly identified as spherical shape of poly-dispersed nanoparticles within the sizes ranging from 15 to $25 \mathrm{~nm}$. From the selected area electron diffraction (SAED) pattern of the AgNPs

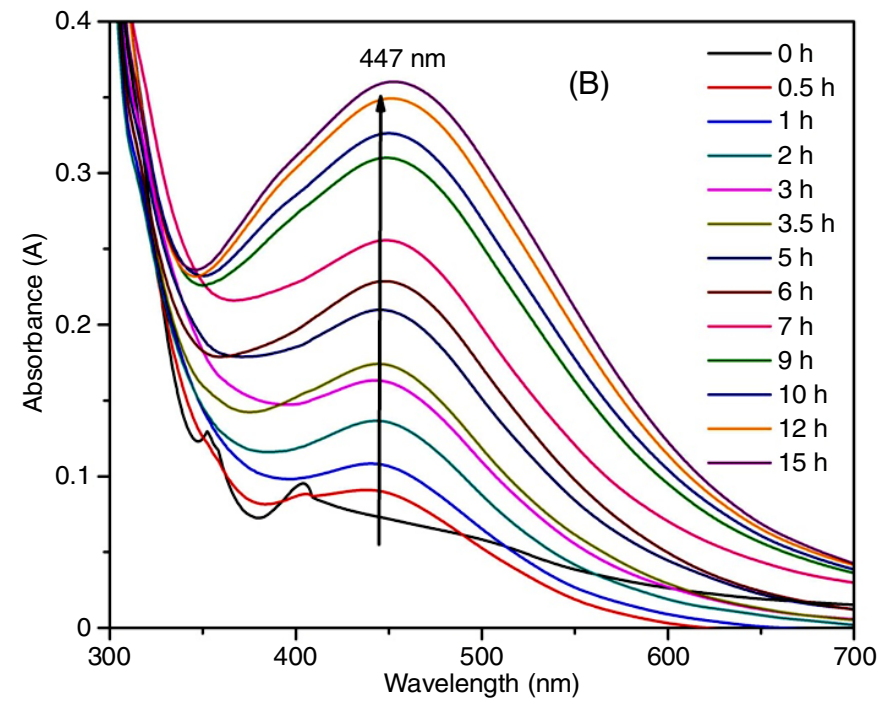

Fig. 1. (A) UV-visible spectra of synthesized AgNPs from silver ions in the presence of P. longifolia stem bark extract; (B) Different time intervals 


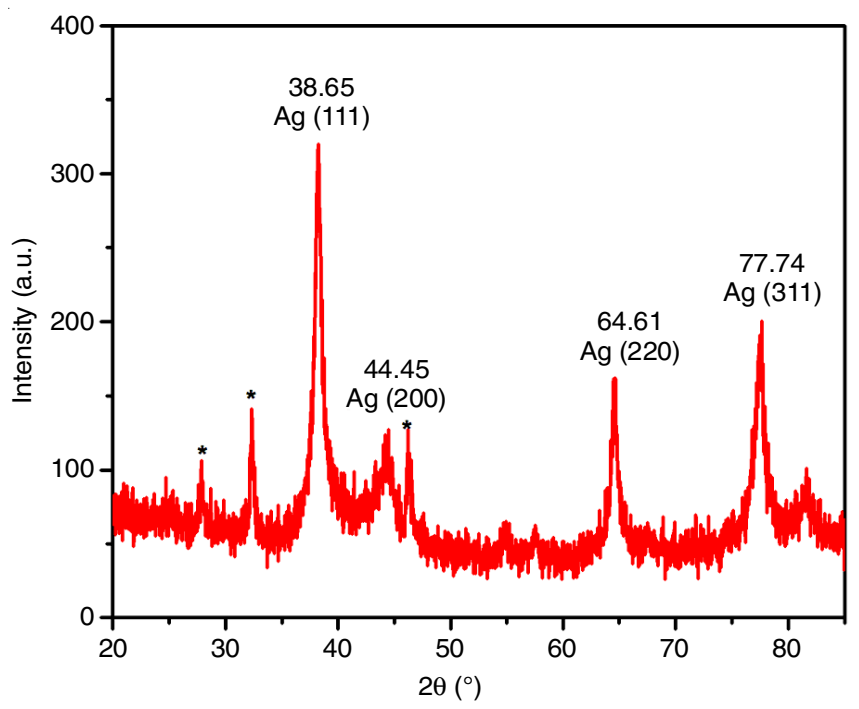

Fig. 2. XRD spectrum of biosynthesized AgNPs
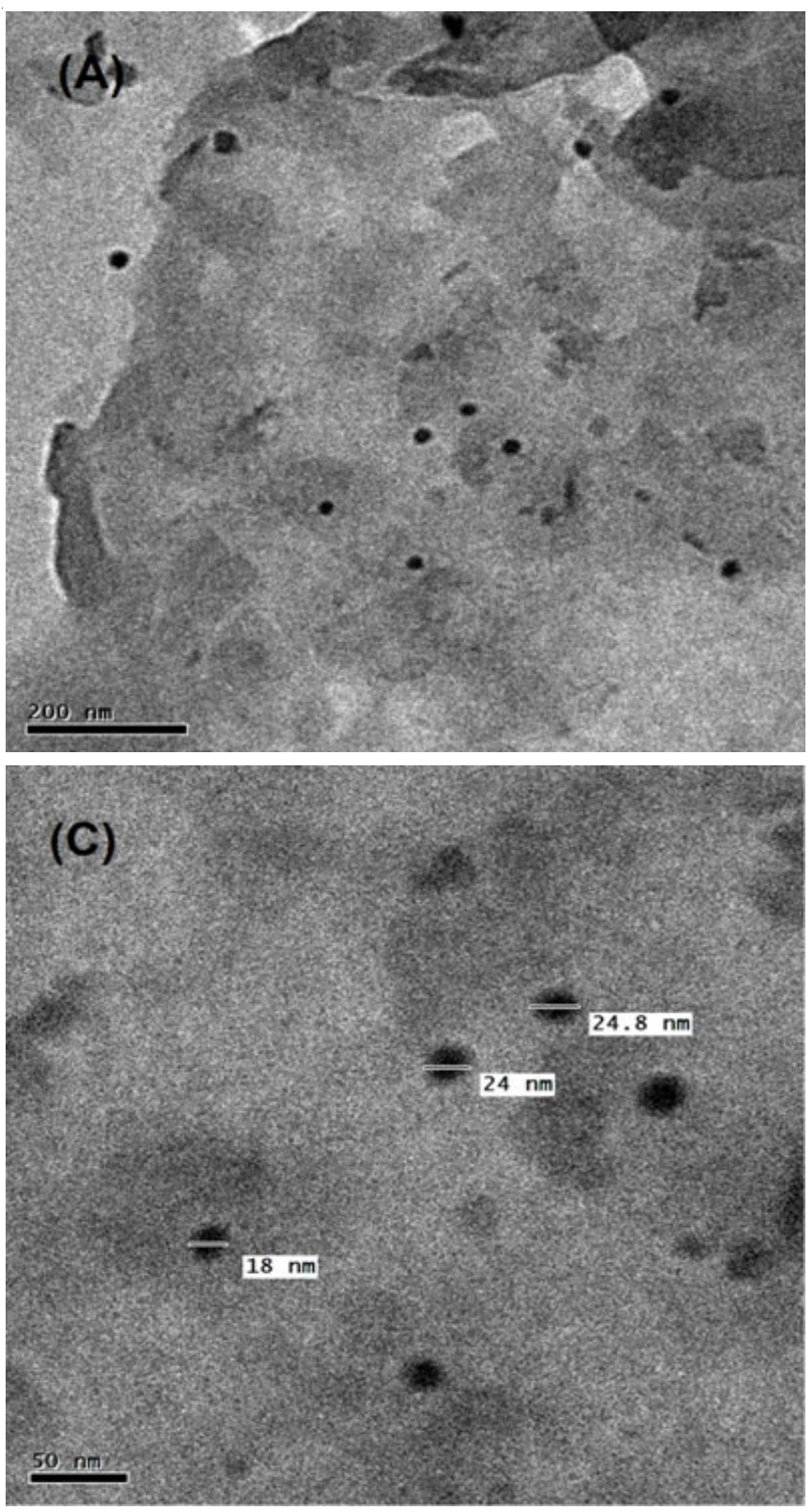

(Fig. 3D) shows four rings of the crystallographic planes of the fcc structure confirms the strong signal of elemental silver.

Catalytic reduction of 4-nitrophenol to 4-aminophenol: The aqueous yellow colour (4-nitrophenol) solution was transformed to colourless (4-aminophenol) in the presence of catalyst AgNPs with excess amount of $\mathrm{NaBH}_{4}$ [20]. The UV-visible spectra of 4-nitrophenol will exhibit the strong absorption peak at $317 \mathrm{~nm}$ [21]. After the addition of excess amount of $\mathrm{NaBH}_{4}$ in the reaction mixture, the appeared red-shift peak at $400 \mathrm{~nm}$ was identified the formation of 4-nitrophenolate ions [22]. In the absence of AgNPs catalyst, the reduction process was not completed upto $240 \mathrm{~min}$ (Fig. 4A). Similarly, another reduction process was examined by adding the plant extract, but absorption center cannot change upto $240 \mathrm{~min}$ (Fig. 4B). After the addition of AgNPs catalyst, this absorption peak at $400 \mathrm{~nm}$ slowly decreased and new peak appeared at $300 \mathrm{~nm}$ (Fig. 4C), thus the product 4-aminophenol was confirmed [21] during the complete reduction reaction within $3 \mathrm{~min}$. As expected, the

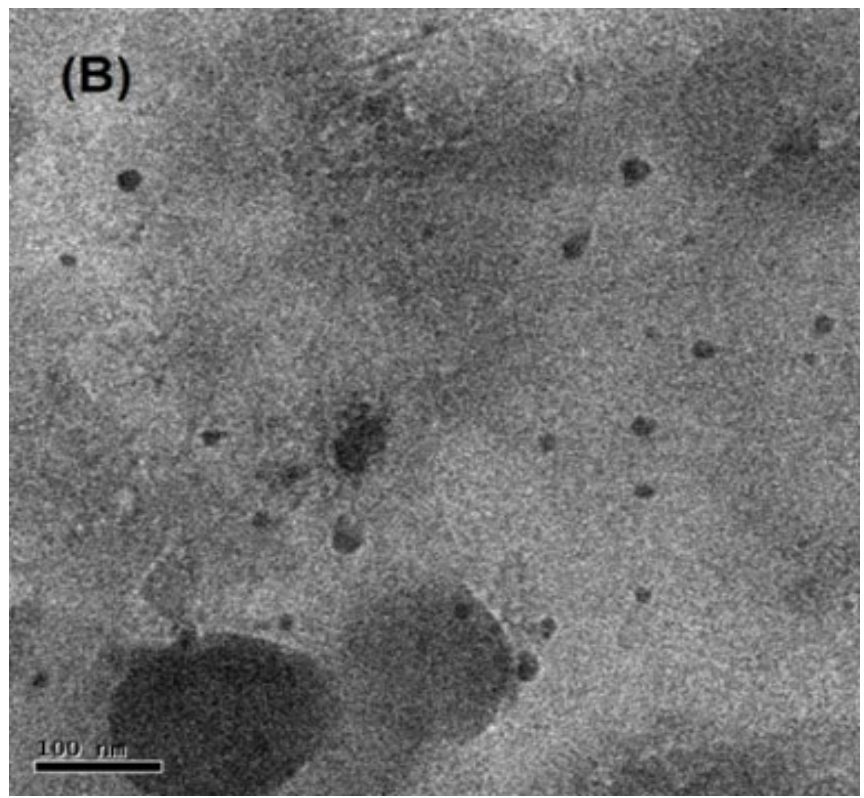

(D)

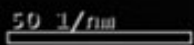

Fig. 3. HRTEM images of biogenic silver nanoparticles (A, B, C); SAED pattern (D) 

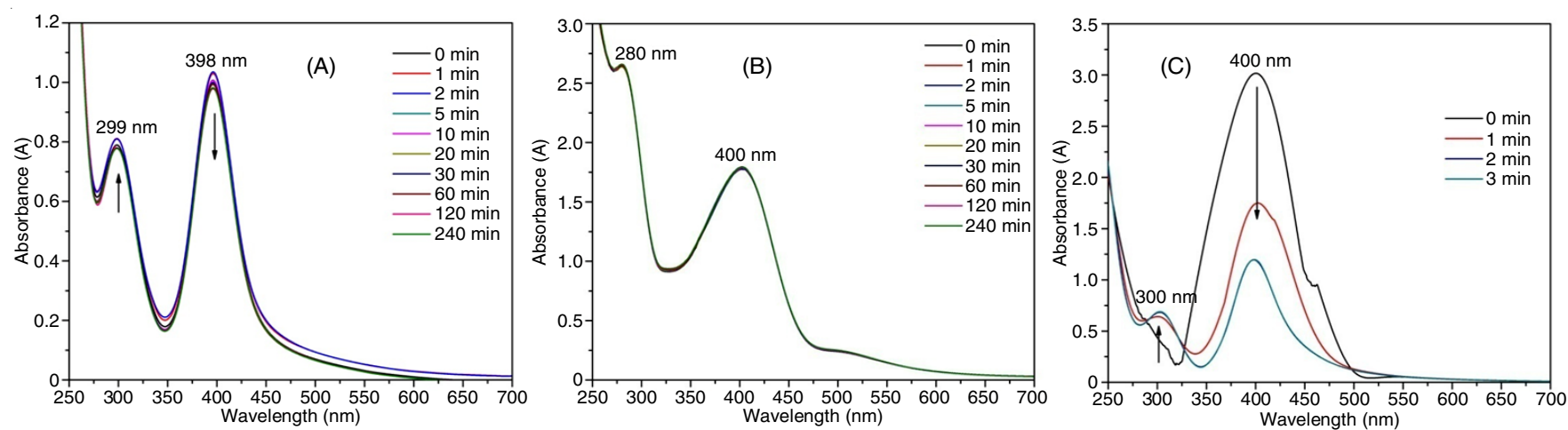

Fig. 4. Catalytic reduction of 4-nitrophenol to 4-aminophenol using green synthesized $\mathrm{AgNPs}$ in the presence of $\mathrm{NaBH}_{4} ;(\mathrm{A}) \mathrm{NaBH}_{4}$ only, in the absence of AgNPs: (B) $\mathrm{NaBH}_{4}$ and plant extract only, in the absence of AgNPs; (C) synthesized AgNPs

Langmuir Hinshelwood mechanism, $\mathrm{BH}_{4}^{-}$ions is electron donor and 4-nitrophenol is electron acceptor with the help of metal nanoparticles [22]. This result corroborates with the previously reported catalytic activities of physico-chemical synthesized metal nanoparticles $[8,23,24]$.

\section{Conclusion}

P. longifolia stem barks extract assisted green synthesis of AgNPs has environmental eco-friendly, non-toxic one step process. UV-visible spectral SPR value at $447 \mathrm{~nm}$ and change of colour has identified the synthesis of AgNPs. HRTEM images show the spherical shape particles with sizes from 15 to $25 \mathrm{~nm}$. Further, the catalytic performance of the synthesized AgNPs acts as an excellent reduction agent for 4-nitrophenol to 4-aminophenol.

\section{ACKNOWLEDGEMENTS}

The authors are thankful to P. Sasirekha, Department of Chemistry, Manonmaniam Sundaranar University, for partial help in this work. Thanks are also due to The Director, Centre for Nanoscience and Nanotechnology, University of Madras, Chennai and The Head, Department of Physics, Manonmaniam Sundaranar University, Tirunelveli, India for the HRTEM and XRD analysis.

\section{CONFLICT OF INTEREST}

The authors declare that there is no conflict of interests regarding the publication of this article.

\section{REFERENCES}

1. M.-C. Daniel and D. Astruc, Chem. Rev., 104, 293 (2004); https://doi.org/10.1021/cr030698+.

2. X. Zheng, D. Wu, T. Su, S. Bao, C. Liao and Q. Wang, ACS Appl. Mater. Interfaces, 6, 19840 (2014); https://doi.org/10.1021/am505177c.

3. J. Chen, Y. Sun, Q. Chen, L. Wang, S. Wang, Y. Tang, X. Shi and H. Wang, Nanoscale, 8, 13568 (2016); https://doi.org/10.1039/C6NR03143A.

4. Y. Liang, C. Lin, J. Guan and Y. Li, RSC Advances, 7, 7460 (2017); https://doi.org/10.1039/C6RA28167B.

5. E.C. Njagi, H. Huang, L. Stafford, H. Genuino, H.M. Galindo, J.B. Collins, G.E. Hoag and S.L. Suib, Langmuir, 27, 264 (2011); https://doi.org/10.1021/la103190n.
6. M. Karuppiah and R. Rajmohan, Mater. Lett., 97, 141 (2013); https://doi.org/10.1016/j.matlet.2013.01.087.

7. A. Rajan, V. Vilas and D. Philip, J. Mol. Liq., 207, 231 (2015); https://doi.org/10.1016/j.molliq.2015.03.023.

8. A. Rostami-Vartooni, M. Nasrollahzadeh and M. Alizadeh, J. Colloid Interface Sci., 470, 268 (2016); https://doi.org/10.1016/j.jcis.2016.02.060.

9. B. Khodadadi, M. Bordbar and M. Nasrollahzadeh, J. Colloid Interface Sci., 493, 85 (2017);

https://doi.org/10.1016/j.jcis.2017.01.012.

10. B. Lang and H.-K. Yu, Chin. Chem. Lett., 28, 417 (2017); https://doi.org/10.1016/j.cclet.2016.10.019.

11. S.K. Bhunia and N.R. Jana, ACS Appl. Mater. Interfaces, 6, 20085 (2014); https://doi.org/10.1021/am505677x.

12. Y.-Y. Wang, Y. Shu, J. Xu and H. Pang, CrystEngComm, 19, 684 (2017); https://doi.org/10.1039/C6CE02165D.

13. G. Manjari, S. Saran, T. Arun, A.V. Bhaskara Rao and S.P. Devipriya, J. Saudi Chem. Soc., 21, 610 (2017); https://doi.org/10.1016/j.jscs.2017.02.004.

14. Z. Hasan, Y.S. Ok, J. Rinklebe, Y.F. Tsang, D.-W. Cho and H. Song, J. Alloys Compd., 703, 118 (2017); https://doi.org/10.1016/j.jallcom.2017.01.326.

15. K.R. Kirtikar and B.D. Basu, Indian Medicinal Plants, International Book Distributors: Dehradhun, p. 562 (1995).

16. U. Danlami, A. Rebecca, D.B. Machan and T.S. Asuquo, J. Appl. Pharm. Sci., 1, 174 (2011).

17. M. Sampath, J. Appl. Pharm. Sci., 3, 148 (2013).

18. S. Kaviya, J. Santhanalakshmi and B. Viswanathan, J. Nanotechnol., 2011, Article ID 152970 (2011); https://doi.org/10.1155/2011/152970.

19. M.R. Bindhu and M. Umadevi, Spectrochim. Acta A Mol. Biomol. Spectrosc., 101, 184 (2013); https://doi.org/10.1016/j.saa.2012.09.031.

20. X. Li, Y. Ma, Z. Yang, D. Huang, S. Xu, T. Wang, Y. Su, N. Hu and Y. Zhang, J. Alloys Compd., 706, 377 (2017); https://doi.org/10.1016/j.jallcom.2017.02.192.

21. K. Muthu and S. Priya, Spectrochim. Acta A Mol. Biomol. Spectrosc., 179, 66 (2017); https://doi.org/10.1016/j.saa.2017.02.024.

22. S. Lu, J. Yu, Y. Cheng, Q. Wang, A. Barras, W. Xu, S. Szunerits, D. Cornu and R. Boukherroub, Appl. Surf. Sci., 411, 163 (2017); https://doi.org/10.1016/j.apsusc.2017.03.120.

23. M. Kohantorabi and M.R. Gholami, New J. Chem., 41, 10948 (2017); https://doi.org/10.1039/C7NJ03009F.

24. S.J. Pawar, S.Y. Patil, P.P. Mahulikar and V.S. Zope, Chem. Phys. Lett., 671, 147 (2017); https://doi.org/10.1016/j.cplett.2017.01.021. 